\title{
Everyday Things Change: Australian Athlete Communication During the Coronavirus Lockdown
}

\author{
Lewis Whales, Stephen Frawley, \\ Adam Cohen, and Natalia Nikolova \\ University of Technology Sydney
}

\begin{abstract}
During the coronavirus (COVID-19) pandemic, Australian professional sport leagues were impacted by temporary league shutdowns. One example is the Suncorp Super Netball, the world's premier netball competition. This commentary paper explores the Suncorp Super Netball league shutdown from the perspective of the players. Our commentary has emerged from an ongoing ethnographic study supported by interviews with two players (a representative on the players association and a club captain) conducted during the league shutdown. Such a shutdown was the first in the history of the league, and it required an unprecedented response, coordinated by interdependent stakeholders. The authors outlined the importance of stakeholder communication in effectively navigating this extraordinary situation. In addition, the authors discussed the usefulness of technology-as-context for teamwork and leadership, given the limitations on physical interaction and geographical separation. In conclusion, the authors proposed recommendations for sport practitioners and potential research directions resulting from the coronavirus-related league shutdown.
\end{abstract}

Keywords: athlete leadership, professional sport, stakeholder communication, technology-as-context

In this commentary paper, we explored the coronavirus (COVID-19) pandemic from the perspective of professional Australian athletes. We discussed the impact that the coronavirus and related competition shutdowns had on athletes with two Suncorp Super Netball (SSN) players, one of whom is a delegate on the Australian Netball Players Association (ANPA) and the other, a club captain. We incorporated these interviews into our analysis, highlighting stakeholder communication and technology-as-context for leadership and teamwork as strategies employed to navigate the coronavirus-related league shutdown. The SSN is the leading domestic netball competition in the world, attracting national representatives from across the globe. This commentary paper has emerged from an ongoing

The authors are with the UTS Business School, University of Technology Sydney, Broadway, NSW, Australia. Whales (lewis.whales@uts.edu.au) is corresponding author. 
ethnographic study exploring leadership in the club context, providing a detailed background into athlete routines and practices before the coronavirus pandemic.

Professional sport leagues represent cartel-like structures of organizations that must cooperate to achieve their individual and collective interests (Smith \& Stewart, 2010). In the case of the SSN, these include the national sporting organization (NSO), state sporting organizations (SSOs), clubs, and players association (ANPA). As the crisis hit Australia, they were all required to understand, determine, and communicate a path forward. To understand how these requirements played out, we chose to interview two players based on their experience, one a representative on the players association (Player 1) and one a team captain (Player 2). Discussions with the players were in the style of narrative interviews. In our analysis, we retraced the athletes' experience in line with public announcements and critical dates. Both players were interviewed in early May, during the league's coronavirus shutdown. We have complemented our commentary with quotes from the two players and others in the public domain.

The purpose of this paper was to serve as an illustration of one league that had to shut down and the coordinated response by stakeholders to communicate important messages in a timely and effective manner. We positioned the paper from the perspective of the athletes; in a short space of time, the players went from having secure, predictable work to being uncertain about their working conditions on a daily basis. The paper analyzes the timeline of events as they unfolded and were experienced by the players and how the players have stayed in contact with relevant stakeholders. We outlined how technology has enabled players to adapt to evolving conditions and suggested how technology-as-context may influence teamwork and leadership. We recommend that in unprecedented events, such as the coronavirus pandemic, league stakeholders cooperate, considering mutual interests. The long-term strength of relationships among stakeholders should be a priority in decision making.

\section{Timeline of Events and Player Experience}

Prior to the league shutdown or any announcements being made by government or league officials, players first experienced the coronavirus threat through rumors, speculation, and a quarantine scare. Player 1 described the first time the team was impacted by the coronavirus; after returning from an away game, the players were informed that a guest from the hotel where the team had stayed had to be tested for COVID-19:

If they tested positive, we would have to be in isolation for 14 days. They said, training is cancelled tomorrow, don't come to training unless we find out the results are negative, then we will train, if they are positive then we won't.

This experience showed the nature of this crisis: ambiguity as to what would happen, even the next day, given the uncertainty surrounding the virus. This uncertainty was only increased by the media and the responses by other leagues, which provided grounds for speculation. Player 2 suggested that actions and discussions by other Australian leagues contributed to speculation about the SSN: "everyone is copycats in this sort of world, NRL [National Rugby League] makes 
announcements, and then AFL [Australian Football League] makes announcements ... in saying that netball has obviously got to consider its own issues." Both players indicated their surprise in terms of the speed and impact of the events that unfolded. They had never contemplated a scenario where the whole competition would shut down and the ramifications that would come as a consequence. Player 1 recalled, "when the coronavirus started, and people started losing their jobs, I didn't assume that it would impact on us, especially financially." Player 2 was equally surprised by the events: "I certainly didn't think a virus could stop us playing ... it's nothing I ever prepared for." It is evident that the situation and related consequences were not anticipated by the players, which can be attributed to the lack of precedent.

This scenario for many sport stakeholders, including players, can be considered a quantum collapse. Lord (2018) described a quantum collapse as all potentialities being limited to one, the present, which is vastly different from anything previously experienced or predicted. The result of the quantum collapse is that there was no precedent, no similar experience to inform any of the stakeholders involved, including the players, about possible actions or measures. This quantum collapse occurred suddenly and forced a hurried response that had to quickly crystalize, an ultimate decision to send the players home, as explained by Player 2: "we got into training that Monday, they said that we can't be here anymore... It was in a matter of hours that all of that happened. By that night we were on a flight home." The required response was to cease training, eliminating face-to-face contact among the players and staff.

On the morning of March 23, the players were notified by the SSO that teams across the competition would be unable to train and the season had been postponed. International players were advised by the players association (via WhatsApp) to consider traveling home because it could be months before they would be able to train again. The decision to cease training and postpone the season was forced due to the implementation of government restrictions. However, this left stakeholders with the collective responsibility to decide how they could respond to the circumstances in order to return in a strong position when it became possible. At this time, the league publicly announced that the season would not start before June 30 (Suncorp Super Netball, 2020a). Next, the players association, the league, and clubs negotiated ongoing pay and conditions while the crisis was ongoing; Player 1 recalled the negotiation:

I think initially they said $70 \%$ pay cut was until the end of May, until they had decided what would happen with the league. They [players association] pushed back and said no, we will take 2 weeks of full paid leave, then three weeks of $30 \%$ until the first of May ... then we renegotiated another deal so the maximum pay cut someone would get would be $50 \%$.

The agreement also included a commitment by the players of $7 \mathrm{hr}$ of training per week. Collectively, the players went from a secure financial position, with a potential average salary in 2020 of \$AUD 75,167 and regimented training schedules, to 2 weeks of leave followed by $70 \%$ pay cuts and a maximum 7-hr club-prescribed training load (Suncorp Super Netball, 2020b). This was reviewed, and on April 24, the SSN league announced that the pay reduction would be capped at $50 \%$ and the training loads would increase to $12 \mathrm{hr}$ per week until May 31; a 
decision on the season moving forward would be made at that time (Suncorp Super Netball, 2020c).

While the initial response did not enable much involvement of the players, the constantly evolving, unprecedented situation led the ANPA to increase meetings with their delegates, which became weekly, whereas previously, they had three to four meetings per year. Each club has two delegates who represent the players in a team and relay messages from the players association meetings back to the team. The delegates aim to capture the important points from the meetings and share them with the team to ensure each player has up-to-date information and access to resources. Virtual meetings provide the opportunity to give feedback; information is also distributed in written form (using mediums including WhatsApp and email) designed to keep players updated. The ANPA has, in addition, conducted virtual "town hall meetings" with the entire playing group, giving staff from the NSO and the SSN the opportunity to speak. This inclusion of players in the decision-making process has given players an agency. Player 2 was surprised by the degree of consultation with the players:

I assumed that everything would be decided without considering the players, which, is harsh, but at the end of the day there are a lot of other stakeholders involved. So, I have appreciated how much input they have allowed us to have.

Additionally, inclusion in scenario planning gave Player 2 a new appreciation for the complexity of the league: "I don't think I considered how many moving parts there would be to something like this ... it has made me appreciate how much goes in to running a sport." Professional sport teams are surrounded by a team of support staff and coaches responsible for carefully planning and communicating training schedules and logistics. Typically, players would know their training schedule weeks in advance and the season schedule months in advance. There are exceptions in some circumstances, for example, with an injury or at finals time; however, last-minute changes are uncommon. From the athletes' perspective, this increased uncertainty during the coronavirus crisis has been navigated through the regular communication with stakeholder groups.

Another positive factor during the crisis has been access to technology, which has facilitated the players' training commitments during the shutdown period and enabled ongoing communication among staff and players. Virtual meetings via Zoom have allowed players to complete bike, yoga, and Pilates sessions as a group, enabling players and staff to stay connected. A weekly session facilitated by the team's sport psychologist has further created a sense of social connection:

We are so social, we have bike sessions on Zoom ... every week our sport psych will do something different. We also have Pilates and yoga. There are lots of times you still see everyone's face and obviously we have WhatsApp groups. (Player 1)

This sentiment was supported by Player 2: "our staff have been good at putting together a pretty good schedule .. . I feel like we are very in touch with each other." It is evident from the accounts of both players that digital solutions have been effective in facilitating a team connection while physical interaction is prohibited. 
Players and the club have also taken responsibility to engage with fans through technology; some of the social-media-savvy players have used their own social media platforms, such as Twitter, Instagram, and Facebook, to let netball fans know what is happening and create a connection with supporters. Player 2 regularly shared content via their personal social media: "I was going live on Instagram every second day, it was a way for me to keep in touch with people and I got some really good feedback." However, Player 1 suggested others have been less comfortable with this approach: "I don't know how to film and everything, but some of the others embrace it and love it. I am more used to interacting with fans on game days." This demonstrates that social media can provide a great medium to stay connected and communicate with other stakeholders, especially fans. However, it does not work for everyone, and in this case, it was used on an ad hoc basis, as well as strategically.

Generally, technology has helped the players to maintain a social connection. The players are used to working closely with teammates and club staff, who not only help each other perform at the highest level, but also form a support network. With players spread out across the country and the world, staying connected with each other and with fans is a priority that has required improvisation. The use of technology has facilitated this connection, overcoming geographical and physical boundaries. Player 1 indicated that ongoing digital interaction sustained the team connection during a time of physical separation: "I think we are actually well connected and it's going to be very exciting when we get back together." Sustained connection through technology has created a positive anticipation of the team returning to training and games.

The next two sections explore how stakeholders have collaborated to make decisions while engaging with players and keeping them informed and how the club and players have utilized technology to stay connected with each other and fans.

\section{Stakeholder Mapping and Collective Leadership}

The cartel-like nature of sport leagues creates an interdependent network of organizations. This network includes the league (in this case, the SSN), NSO, SSO, individual clubs, and the players association. Each of these organizations is able to affect or be affected by the operations of the league and, thus, is considered a stakeholder (Freeman, 1984). These organizations represent the stakeholders with the greatest vested interest with concern to the players. According to Ferkins and Shilbury (2015), engaging stakeholders with the greatest vested interest may foster reciprocity and a commitment to each other, rather than a focus on individual interests alone. In the response to the pandemic, it may have been tempting to neglect the interest of other parties for each to protect their own. However, this could have led to negative repercussions for the long term due to, for example, an uncoordinated response to the crisis that would only have increased the players' sense of uncertainty. Instead, stakeholders acted with concern for the collective interests of the group, demonstrating collective leadership.

Collective leadership is a form of leadership that has previously been studied in the context of complex organizational arrangements (White, Currie, \& Lockett, 2016). It is relevant to league stakeholders, given the interdependent nature of the 
network: no organization has the capacity to navigate the situation successfully without the cooperation of the others (Gronn, 2002). Collective leadership fosters recognition of the differences and the needs of each party and may, in fact, produce better long-term results. This is demonstrated through the players' appreciation for being included in decisions and the recognition of mutual interests. When facing high uncertainty, it may be more difficult to achieve collective leadership, but it is then that it is most needed (Gibeau, Langley, Denis, \& van Schendel, 2020).

The decision to cease training and therefore postpone the season was taken out of the hands of the SSN league officials by the announcement of government restrictions. However, the specifics of what the shutdown would look like could not be decided without consultation with the other stakeholders. Thus, the league, clubs, and players association all worked to agree to terms. Publicly, the SSN CEO, Chris Symington, commented (Suncorp Super Netball, 2020c, para. 7),

It really is a credit to our sport how well all parties have approached these discussions. It's not an easy time for anyone and I'm proud of our clubs' and playing group's maturity and willingness to ensure the league will survive and bounce back strong.

This process of collaborating and making joint decisions may seem simple retrospectively; however, there are many factors that had to be considered, including club membership, sponsors, broadcasters, employees, game attendance, training facilities, support and resources, player welfare, short- and long-term objectives, and many others. The ANPA CEO, Kathryn Harby-Williams, stated, "whilst the environment remains extremely difficult for our athletes, they continue to be considerate of the circumstances which confront our sport and will continue to play their role to help it get through these difficult times" (Suncorp Super Netball, 2020c, para. 12).

A key to successful collective leadership is inclusion, according to White et al. (2016) - inclusion in decisions fosters trust that will support ongoing negotiations. In the case of the SSN, collective leadership is demonstrated among the network of stakeholders. Initially, action was forced by government restrictions; however, the subsequent response engaged a network of stakeholders in a collaborative decision-making process. Collaboration was demonstrated between the league, NSO, $\mathrm{SSO}$, club, and players association to communicate the initial decision to the players. Subsequently, the players were consulted by the league, NSO, and clubs in further decisions, such as scenario planning for the league's return.

\section{Staying in Contact}

When the players were no longer able to gather as a team, they suddenly became a virtual team. However, this team had the benefit of having already developed strong relationships between group members. The 2 -week leave period gave the team an opportunity to develop a schedule that allowed the group to continue working together despite the physical distance between the members. Technology has facilitated the virtual team approach through Zoom and WhatsApp. The players and club staff had to quickly adjust from a context of close and regular face-to-face interaction to virtual interaction via technology as context for leadership and 
teamwork. Larson and DeChurch (2020) reviewed the literature on technology and leadership and determined that (a) the technology used influences the leadership practice in teams and (b) sharing leadership is beneficial for team leadership.

Using Zoom (video and audio) as a platform to conduct group training sessions facilitates interaction between group members, as opposed to other options that could involve players completing prescribed workouts on their own, thus not having the opportunity to practice leadership through interaction (Larson \& DeChurch, 2020). The players indicated that the virtual presence of their teammates and coaches has allowed them to feel motivated and connected, an experience Player 1 sometimes lacks when doing self-workouts: "when I do a session by myself it is quite lonely ... but with the computer screen, you randomly have people talking to you, it feels like you are actually with people." In video sessions, players and staff could interact while completing group activities, therefore replicating face-to-face sessions. The ability for all team members to participate in technologically enabled conversations encourages shared responsibility (Larson \& DeChurch, 2020). For example, Zoom bike sessions provided the opportunity for players to "take turns" in running the workouts. Thus, using technology to enable the sharing of responsibilities was an important step toward facilitating connections within the group.

WhatsApp groups support group interaction outside of designated training times. Players noted that they have a group with all players and a group with players and staff to share information and socialize. It is evident that the efforts to stay connected have been successful. At the point of the interviews, Player 1 was feeling "almost more connected," and Player 2 was feeling "more in touch."

\section{Engagement With Fans Through Technology}

Product-related social media posts from sport clubs gain more attention than nonproduct-related posts (Maderer, Parganas, \& Anagnostopoulos, 2018). However, during the coronavirus shutdown, clubs face the dilemma of not being able to produce product-related posts. Innovative players and clubs have, instead, produced content including video diaries, Instagram takeovers, and Zoom drop-ins to give fans an insight into how they are handling the pandemic. Player 2 aimed to provide fans with entertainment and appreciated the importance of fans: "when we go back, we are going to need fans and members to help us get on our feet." Players have also used their personal platforms to advocate important health-related messages to the public. Athlete advocacy on social media may influence societal opinions (Fallon, Santarossa, \& Woodruff, 2018). Player-created content has enabled engagement avenues between players and fans that previously were not utilized. Initially, Player 2 used their increased time to engage with fans: "I was [on] Instagram live, having a live chat, with four or five young girls a day." This is one example of how technology has enabled the coordinated effort between club and players to engage with the community of members and fans during the coronavirus pandemic.

\section{Recommendations and Ongoing Questions}

The coronavirus pandemic has caused devastation for the health and financial wellbeing of people across the world. As of May 11, the World Health Organization 
(2020) has reported nearly 280,000 deaths, and a significant portion of advanced economies are expected to enter a recession in 2020 (International Monetary Fund, 2020). The sport industry in Australia has not been immune to the impacts of the coronavirus, particularly when it comes to financial ramifications. The crisis can be regarded as a quantum collapse for those employed in professional sport; however, through collaboration, interdependent stakeholders have been able to adapt to navigate the situation. Collective leadership demonstrated during this time may place organizations in the optimal position to succeed when competition returns. This relates to cooperation between and within organizations. Between organizations, collective leadership gives "voice" to each stakeholder group and fosters ongoing trust. Within organizations, technology has facilitated the temporary shift to virtual teams, enabling the ongoing interaction between players, staff, administrators, and fans. Once competitions return, team resilience and trust developed under adversity will persist. Innovations that stakeholder groups, players, and clubs have introduced may remain and become best practice. A new appreciation may also develop for existing practices.

The coronavirus competition shutdowns and beyond can be used as an opportunity to study collaboration and leadership in professional sport organizations. It should be noted we have not had the capacity (time and resources) to explore communication, teamwork, and leadership in situ. Researching the content and context of communication between parties could reveal informal influences that cannot be conveyed in interviews, an aspect that is worthy of further attention.

We provide recommendations for practitioners based on this commentary, as well as arising research questions.

Recommendations for practitioners:

1. Engaging stakeholders in decision making complicates the process; however, it builds trust among interdependent parties, which is especially important when parties face high uncertainty.

2. Uncertainty results in a greater need for communication, even before the answers to questions may exist. It has proven beneficial to be transparent when answers are not known and to identify a point in the future when more information will be provided.

3. Communication technology use can help teams interact during times of physical separation; however, numerous factors must be taken into consideration, including individual access to technology; group size; activities; and permission within the technology, allowing for group contribution.

4. Social media technology has provided a useful means for players to remain in direct contact with fans through their own and club channels. It is important to acknowledge that players have different comfort levels with the use of digital and social media platforms.

The SSN is an example of a professional sport league that has been significantly disrupted by the coronavirus pandemic. In this commentary, we have explored the experience of players in the first 2 months of the pandemic and league shutdown. We have described how government restrictions required a response from the league. Following the restrictions, the league, NSO, SSO, clubs, and players association have collaborated to navigate a path forward. At the time of writing this commentary, 
we are still in the midst of the coronavirus competition shutdown and, as the SSN plans to recommence, a number of questions need to be addressed. It appears the initial stages of the response have been relatively successful through regular communication and cooperation among stakeholders, as well as the use of technology as a communication tool. However, a decision about competition recommencing had not yet been determined. Questions about recommencement and adjustment to a postpandemic environment still remain, providing an opportunity for scholars in a unique circumstance. Several future research questions arise from the coronavirus league shutdown:

1. How will clubs and players adapt to a postcoronavirus environment when competitions return but social distancing rules remain?

2. To what extent will technology endure as a useful tool for meeting in professional sport beyond the coronavirus?

3. How does team structure influence connection and shared leadership in virtual environments?

4. How will players and clubs continue to engage fans if they are not allowed to attend games for an extended period of time?

Over the coming months, further questions will emerge as the stakeholders collectively navigate unprecedented circumstances for professional sport.

\section{Acknowledgments}

This research is supported by an Australian Government Research Training Program Scholarship.

\section{References}

Fallon, M.R., Santarossa, S., \& Woodruff, S.J. (2018). Athletes as advocates: Influencing eating-disorder beliefs and perceptions through social media. International Journal of Sport Communication, 11(4), 433-446. doi:10.1123/ijsc.2018-0112

Ferkins, L., \& Shilbury, D. (2015). The stakeholder dilemma in sport governance: Toward the notion of "stakeowner". Journal of Sport Management, 29(1), 93-108. doi:10. 1123/JSM.2013-0182

Freeman, R.E. (1984). Strategic management: A stakeholder approach. Boston, MA: Pitman.

Gibeau, É., Langley, A., Denis, J.-L., \& van Schendel, N. (2020). Bridging competing demands through co-leadership? Potential and limitations. Human Relations, 73(4), 464-489. doi:10.1177/0018726719888145

Gronn, P. (2002). Distributed leadership as a unit of analysis. The Leadership Quarterly, 13(4), 423-451. doi:10.1016/S1048-9843(02)00120-0

International Monetary Fund. (2020). World Economic Outlook (April 2020). Retrieved from https://www.imf.org/external/datamapper/datasets/WEO

Larson, L., \& DeChurch, L. (2020). Leading teams in the digital age: Four perspectives on technology and what they mean for leading teams. The Leadership Quarterly, 31(1), 101377. doi:10.1016/j.leaqua.2019.101377

Lord, R.G. (2018). Leadership and the medium of time. In R.E. Riggio (Ed.), What's wrong with leadership? Improving leadership research and practice (pp. 150-172). New York, NY: Routledge. 
Maderer, D., Parganas, P., \& Anagnostopoulos, C. (2018). Brand-image communication through social media: The case of European professional football clubs. International Journal of Sport Communication, 11(3), 319-338. doi:10.1123/ijsc.2018-0086

Smith, A.C., \& Stewart, B. (2010). The special features of sport: A critical revisit. Sport Management Review, 13(1), 1-13. doi:10.1016/j.smr.2009.07.002

Suncorp Super Netball. (2020a, March 23). Suncorp super netball 2020 season on hold. Retrieved from https://supernetball.com.au/news/suncorp-super-netball-2020-season-hold

Suncorp Super Netball. (2020b, March 28). Players agree to five week payment reduction. Retrieved from https://supernetball.com.au/news/players-agree-five-week-paymentreduction

Suncorp Super Netball. (2020c, April 24). Suncorp super netball players payments updated. Retrieved from https://supernetball.com.au/news/suncorp-super-netball-players-paymentsupdated

White, L., Currie, G., \& Lockett, A. (2016). Pluralized leadership in complex organizations: Exploring the cross network effects between formal and informal leadership relations. The Leadership Quarterly, 27(2), 280-297. doi:10.1016/j.leaqua.2016.01.004

World Health Organization. (2020). Coronavirus disease (COVID-19) situation report-112. Retrieved from https://www.who.int/emergencies/diseases/novel-coronavirus-2019 